\title{
Nitrogen-doped micropores binder-free carbon-sulphur composites as the cathode
} for long-life lithium-sulphur batteries

Yuechao Yao ${ }^{a}$, Peng Liua ${ }^{a}$ Qi Zhang ${ }^{b}$, Shaozhong Zenga, Shuangshuang Chen ${ }^{a}$, Guangjin Zou ${ }^{\mathrm{a}}$, Xiaohua $\mathrm{Li}^{\mathrm{a}}$, Xierong Zeng, ${ }^{\mathrm{a}, \mathrm{c}}$, Jizhao Zou ${ }^{\mathrm{a}, \mathrm{c} *}$.

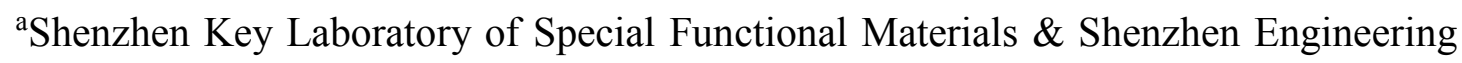
Laboratory for Advance Technology of ceramics, College of Materials Science and Engineering, Shenzhen University, Shenzhen, 518060. P.R. China

${ }^{\mathrm{b}}$ School of Aerospace, Transport and Manufacturing, Cranfield University, Cranfield, Bedfordshire, MK43 0AL, UK

${ }^{\mathrm{c}}$ Guangdong JANUS Intelligent Group Corporation Limited, Dongguan, China

* Corresponding author. E-mail address: zoujizhao@szu.edu.cn (J.Z.Zou)

\section{Abstract}

Nitrogen-doped micropore-contained carbon nanofibres (NMCNFs) were prepared by carbonizing ZIF-8 grown in liquid-phase along with electrospinning. When NMCNFs act as sulphur host materials in lithium-sulphur batteries, NMCNFs can retard the shuttle effect and dissolution of polysulfides through the synergic action of effective physical confinement to micropores and nitrogen surface chemical absorption. NMCNFs show a capacity up to $636 \mathrm{mAh} \mathrm{g}^{-1}$ after 500 cycles against Li anode.

Keywords: Lithium-sulphur batteries, long life, binder-free cathode

\section{Introduction}

Lithium-sulphur batteries with high theory capacity $\left(1675 \mathrm{mAh} \mathrm{g}^{-1}\right)$ have been a focus of research owing to element sulphur being cheap, abundant, environmental friendly [1]. However, some serious questions are deeply restricting the application of lithium- 
sulphur batteries. Firstly, element sulphur has low conductivity $\left(5.0 \times 10^{-30} \mathrm{~S} \cdot \mathrm{cm}^{-1}\right)$ and its discharge products $\left(\mathrm{Li}_{2} \mathrm{~S}, \mathrm{Li}_{2} \mathrm{~S}_{2}\right)$ are insulated too; secondly, the reaction intermediates, lithium polysulfides $\left(\mathrm{LiS}_{\mathrm{n}}\right)$, are highly soluble in organic electrolytes and are easily reduced on the lithium-anode surface; Thirdly, the sulphur expansion/contraction ( $\sim 80 \%)$ in charge-discharge process against lithium results in the disconnection of electrode material with current collector [2,3], which will lead to fast capacity decay and unstable coulombic efficiency.

Carbon nanofibres (CNFs) are good sulphur hosts because of their excellent conductive network and binder-free characterises. Polyacrylonitrile (PAN)-based CNFs have high spinnability, high carbon yield, and high nitrogen doped with nitrile groups [4]. However, the low specific surface area of PAN-based porous CNFs commonly cannot be used as an effective sulphur host material because of lacking the sites for the absorption of sulphur/polysulfides. Thus, the obtained nitrogen-doped nanoporous flexible carbon nanofibres for sulphur host materials are highly desired.

In this paper, we prepared high SSA nitrogen-doped micropore flexible carbon nanofibres (NMCNFs) by electrospinning ( $\mathrm{ZnBr}_{2} / \mathrm{PAN}$ nanofibres) and liquid phase growth (ZIF-8/ZnBr $2 / \mathrm{PAN}$ nanofibres), followed by pyrolysis process. Furthermore, the NMCNFs/S composites were synthesized via vapour diffusion of commercial sulphur powder. The electrochemical properties of the NMCNFs/S samples were also investigated as promising electrodes for lithium-sulphur batteries.

\section{Experimental}

\subsection{The synthesis of NMCNFs.}




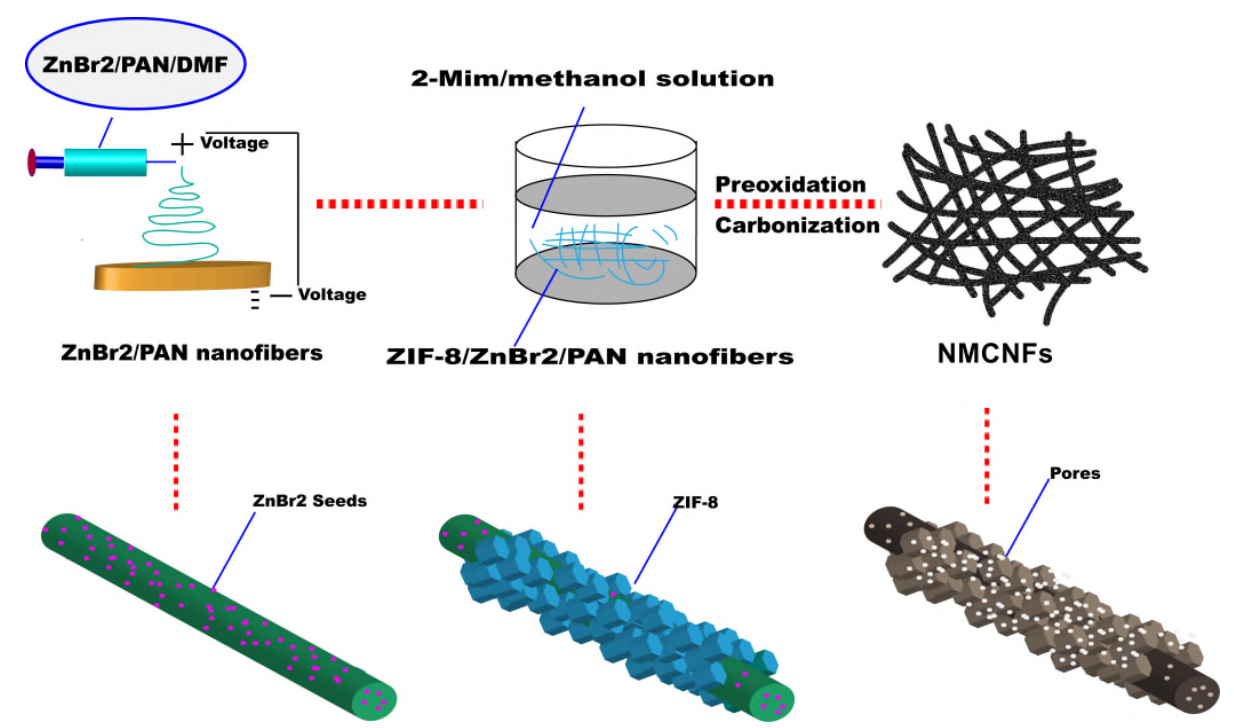

Fig. 1 Schematic illustration of the NMCNFs preparation process.

The fabrication process for high SSA nitrogen-doped micropore flexible carbon nanofibres (NMCNFs) is illustrated schematically in Fig. 1. The $\mathrm{ZnBr}_{2} / \mathrm{PAN}$ composite nanofibres were synthesized by electrospinning. The $2.2 \mathrm{~g} \mathrm{ZnBr}_{2}$ particles were dispersed in $4 \mathrm{ml} \mathrm{N}$, N-dimethylformamide by sonication. Polyacrylonitrile was completely dissolved in $7 \mathrm{ml} \mathrm{DMF}$ solution with a vigorous stirring at room temperature. Then, these two solutions were mixed and stirred for $24 \mathrm{~h}$ at room temperature. The 2.3 $\mathrm{g}$ sheet-type $\mathrm{ZnBr}_{2} / \mathrm{PAN}$ nanofibres were dipped into a mixed solution of 2methylimidazole $(13 \mathrm{~g})$ and methanol $(400 \mathrm{ml})$ for 3 days. The obtained ZIF$8 / \mathrm{ZnBr}_{2} / \mathrm{PAN}$ nanofibres were washed twice by methanol. Afterwards, ZIF$8 / \mathrm{ZnBr}_{2} / \mathrm{PAN}$ nanofibres were left in air at $220{ }^{\circ} \mathrm{C}$ for $180 \mathrm{~min}$ and subsequently carbonized under Ar flow at $900{ }^{\circ} \mathrm{C}$ for $2 \mathrm{~h}$ with a rate of $5{ }^{\circ} \mathrm{C} \mathrm{min}^{-1}$.

\subsection{The synthesis of NMCNFs/S composites.}

The obtained high SSA NMCNFs were cut into electrodes $(\phi=15 \mathrm{~mm})$. Then, the NMCNFs/S cathodes were synthesized via vapour diffusion of commercial sulphur powder. Firstly, the NMCNFs nanosheet and sulphur was sealed in a glass bottle and 
heated to $200^{\circ} \mathrm{C}$ at a heating rate of $2{ }^{\circ} \mathrm{C} / \mathrm{min}$ in an oven and maintained at $200{ }^{\circ} \mathrm{C}$ for $4 \mathrm{~h}$ (sulphur and NMCNFs are separated). Then, the temperature was raised to $250{ }^{\circ} \mathrm{C}$ and maintained $2 \mathrm{~h}$.

\subsection{The fabrication of electrode and electrochemical measurements}

The obtained NMCNFS cathodes were used after being dried at $60{ }^{\circ} \mathrm{C}$ for $12 \mathrm{~h}$ under vacuum. The loading amount of sulphur is about $1.5-2.0 \mathrm{mg} / \mathrm{cm}^{2}$ in a cell and the amount of electrolyte is $30 \mu \mathrm{L} / \mathrm{mg} \mathrm{S}$. The charge-discharge tests were conducted on NEWARE instruments with voltage window of $1.5 \sim 3.0 \mathrm{~V}$ versus $\mathrm{Li}^{+} / \mathrm{Li}$. Cyclic voltammetry (CV) experiment was performed on a $\mathrm{CHI} 660 \mathrm{E}$ electrochemical workstation at a scan rate of $0.2 \mathrm{mV} / \mathrm{s}$ from 3.0 to $1.5 \mathrm{~V}$. The frequency range is from $10^{5}$ to $0.05 \mathrm{~Hz}$ and the perturbation amplitude was $5 \mathrm{mV}$.

\section{Results and discussion}

Fig. 2a shows that $\mathrm{ZnBr}_{2}$ is evenly anchored in PAN nanofibres as ZIF-8 seeds. As shown in the Fig. $2 b$, the $\mathrm{ZIF}-8 / \mathrm{ZnBr}_{2} / \mathrm{PAN}$ nanofibres are successfully synthesized and the polyhedrons of ZIF-8 are fully distributed in the outer surface of $\mathrm{ZnBr}_{2} / \mathrm{PAN}$ nanofibres. 

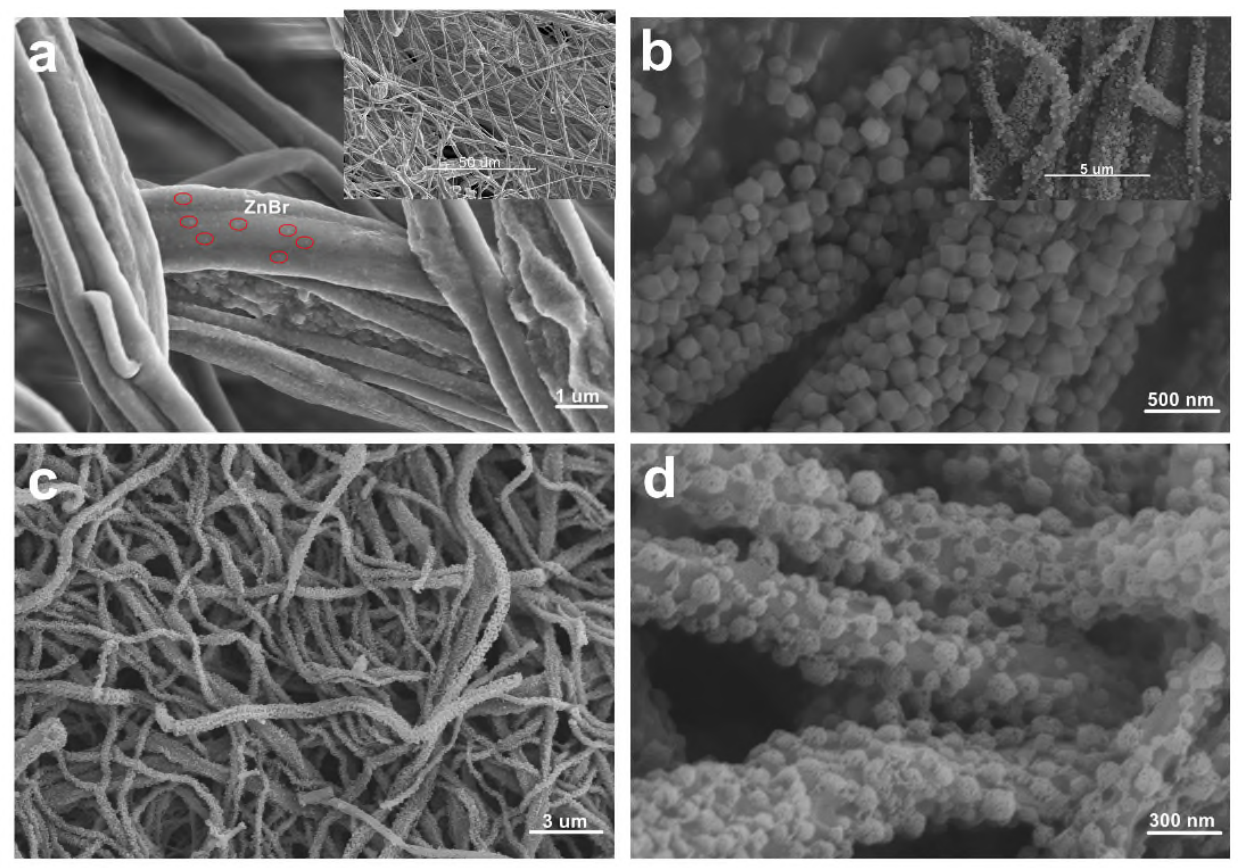

Fig. 2 Field emission scanning electron microscopy (FESEM) image of (a) $\mathrm{ZnBr}_{2} / \mathrm{PAN}$ nanofibres, (b) $\mathrm{ZIF}-8 / \mathrm{ZnBr}_{2} / \mathrm{PAN}$ nanofibres, (c-d) NMCNFs.

After pre-oxidation and pyrolysis process, the NMCNFs were obtained (Fig.2c-d). Fig.

$2 \mathrm{c}$ shows that the diameter of NMCNFs is relatively uniform, and Fig. $2 \mathrm{~d}$ shows the ZIF-8-derived nanopores on the surface of carbon nanofibres.

The NMCNFs show a high BET surface area $\left(693.64 \mathrm{~m}^{2} \mathrm{~g}^{-1}\right)$, and the total pore volume and average pore diameter are $0.36 \mathrm{~cm}^{3} \mathrm{~g}^{-1}$ and $0.72 \mathrm{~nm}$ respectively. Fig. 3a indicates the existence of many micropores. It has been reported that micropores could effectively absorbed chain polysulfide [5-7].

The microstructure of NMCNFs/S composites was investigated by X-ray diffraction (Fig. 3b). A weak peak of crystalline sulphur can be observed, except for peaks of NMCNFs at $\sim 24^{\circ}$ and $\sim 44^{\circ}$ in the XRD pattern correspond to the $\left(\begin{array}{lll}0 & 0 & 2\end{array}\right)$ and $\left(\begin{array}{lll}1 & 0 & 0\end{array}\right)$ diffractions of carbon materials. The result demonstrates that sulphur is uniformly distributed in the NMCNFs. 

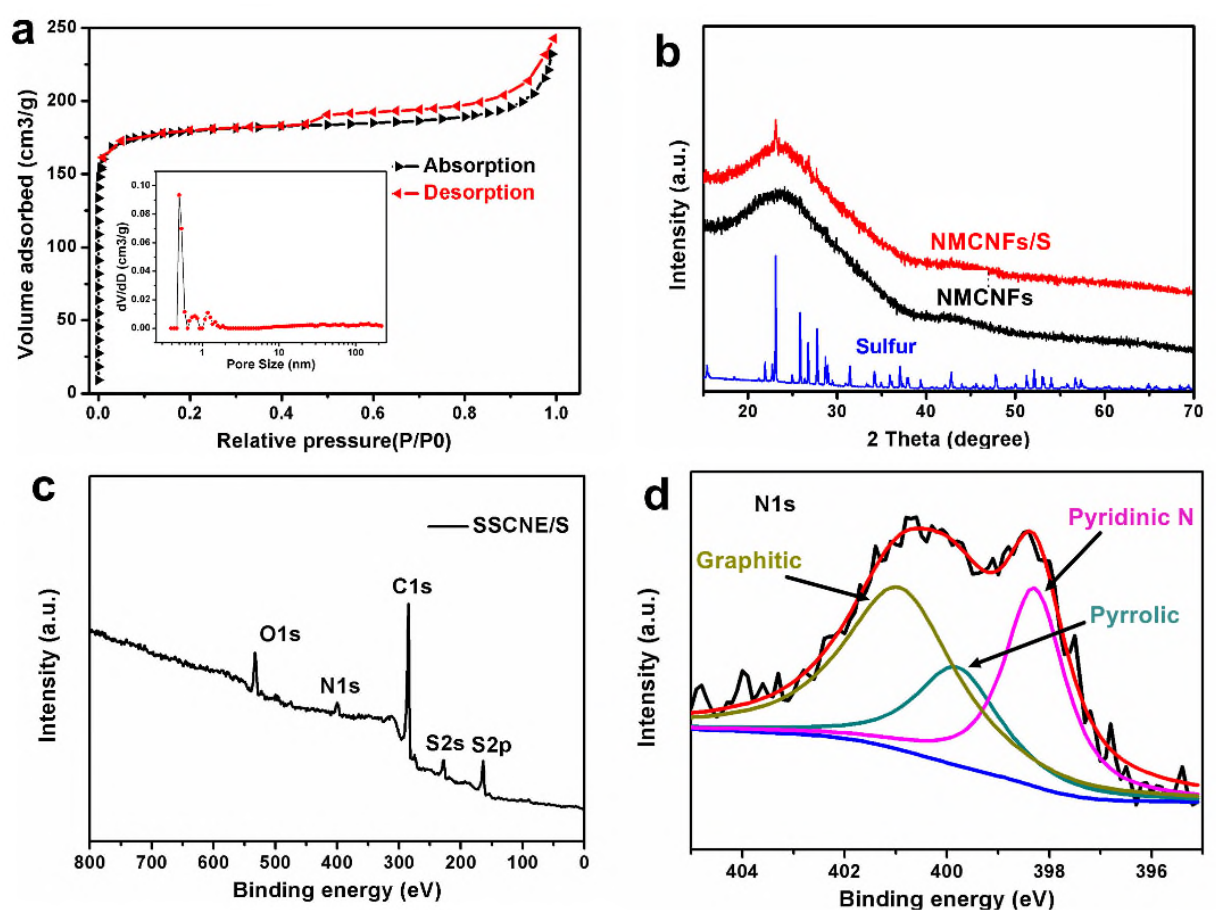

Fig. 3 (a) $\mathrm{N}_{2}$ adsorption-desorption isotherms for NMCNFs and inset of pore diameter distribution (b) X-ray diffraction patterns of sulphur, NMCNFs and NMCNFs/S. (c) XPS spectra of NMCNFs/S . (d) NMCNFs/S high-resolution XPS spectra of the deconvoluted N 1s peak.

Fig. $3 \mathrm{c}$ shows that there are five obvious peaks that correspond to C1s, N1s, O1s, S2p and S2s. The high resolution N1s XPS spectrum (Fig. 3d) is divided into quatemary-N (401.1 eV), pyrrolic-N (399.8 eV), and pyridinic-N (398.3 eV), respectively [8]. Because pyrrolic- $\mathrm{N}$ and pyridinic- $\mathrm{N}$ have a lone pair of electrons and high electronegativity, they take an effective absorption of polysulfides [9, 10].

Fig. 4a shows the CV curves. In the first cycle, a peak at $1.56 \mathrm{~V}$ appears, which is attributed to the formation of insoluble $\mathrm{Li}_{2} \mathrm{~S}_{2}$ and $\mathrm{Li}_{2} \mathrm{~S}$ from small sulphur molecule $\mathrm{S}_{2}$ $4[5,7]$. In the second cycle, the cathodic peak shifts from $1.56 \mathrm{~V}$ to $1.62 \mathrm{~V}$ because of the formation of the complexes that have a lower absorbing energy after the initial cycle [11-13]. 

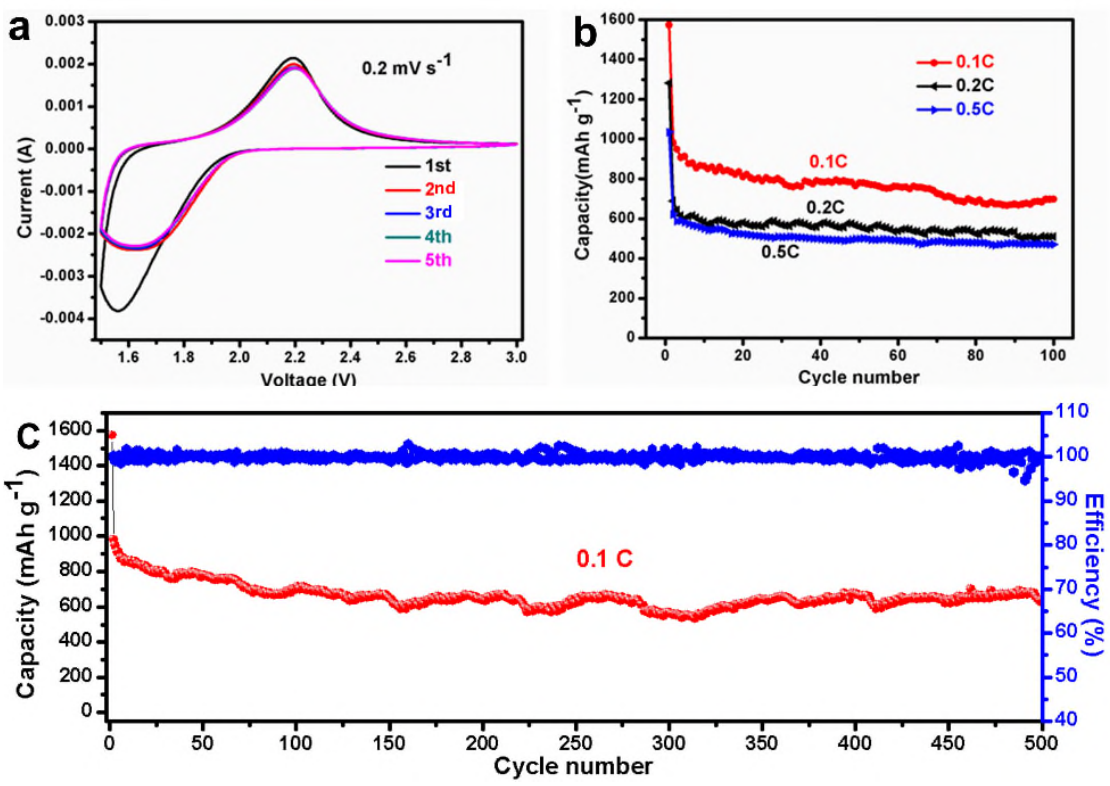

Fig. 4 (a) CV curves at a scanning rate of $0.2 \mathrm{mV} \mathrm{s}^{-1}$. (b) The cyclic performance at different current densities. (c) The cyclic performance and coulombic efficiency at $0.1 \mathrm{C}$.

In the subsequent cycles, the CV curves almost overlap, which exhibits a high reversibility of NMCNFs/S cathodes. Fig. $4 b$ exhibits the discharge capacity at various rates. The initial discharge capacities are 1573, 1282 and $1034 \mathrm{mAh} \mathrm{g}^{-1}$ under $0.1 \mathrm{C}$, $0.2 \mathrm{C}$ and $0.5 \mathrm{C}$, respectively. In the second cycle, the discharge capacities are dramatically decreased to 981,688 and $622 \mathrm{mAh} \mathrm{g}^{-1}$, respectively. These results may be attributed to the residual sulphur of not wrapped by micropores causing irreversible capacity loss after reaction with lithium. The specific capacity of NMCNFs/S cathodes was reduced when the discharge rate was increased, which illustrates that the low rate cycle is beneficial to achieving high specific capacity of micropores-confined sulphur materials. The coulombic efficiency (Fig. 3c) is stable and almost reaches to $100 \%$, which indicates the excellent reaction reversibility for NMCNFs/S cathodes. Meanwhile, the NMCNFs/S cathode shows a stable cycle performance at $0.1 \mathrm{C}$ rate (after 500 cycles, the capacity still shows up to $636 \mathrm{mAh} \mathrm{g}^{-1}$ ).

\section{Conclusions}


The obtained NMCNFs act as a binder-free sulphur host materials that show an excellent cycle stability and retain a high capacity of $636 \mathrm{mAh} \mathrm{g}^{-1}$ after 500 cycles because of its unique microstructure, high SSA $\left(693 \mathrm{~m}^{2} \mathrm{~g}^{-1}\right)$, nitrogen-doped and conductive nanofibre network. Overall, this work not only provides a design for high performance flexible binder-free cathode in lithium-sulphur batteries, but also suggests a facile synthesis method for the design of carbon nanofibres materials with micropores.

\section{ACKNOWLEDGMENTS}

This work was financially supported by the National Natural Science Foundation of China (No.51202150, 51272161,21703141), Program of Introducing Innovative Rese arch Team in Dongguan (No.2014607109)

\section{Reference}

[1] Z.W. Seh, Y. Sun, Q. Zhang, Y. Cui, Chem Soc Rev, (2016).

[2] A. Manthiram, Y. Fu, S.H. Chung, C. Zu, Y.S. Su, Chem Rev, 114 (2014) 11751-11787.

[3] P.G. Bruce, S.A. Freunberger, L.J. Hardwick, J.M. Tarascon, Nat Mater, 11 (2012) 19-29.

[4] X. Li, Y. Chen, H. Huang, Y.-W. Mai, L. Zhou, Energy Storage Materials, 5 (2016) 58-92.

[5] S. Niu, G. Zhou, W. Lv, H. Shi, C. Luo, Y. He, B. Li, Q.-H. Yang, F. Kang, Carbon, 109 (2016) 1-6.

[6] N. Jayaprakash, J. Shen, S.S. Moganty, A. Corona, L.A. Archer, Angew Chem Int Ed Engl, 50 (2011) 5904-5908.

[7] Z. Li, L. Yuan, Z. Yi, Y. Sun, Y. Liu, Y. Jiang, Y. Shen, Y. Xin, Z. Zhang, Y. Huang, Advanced Energy Materials, 4 (2014) -

[8] S. Chu, Y. Zhong, R. Cai, Z. Zhang, S. Wei, Z. Shao, Small, 12 (2016) 6724-6734.

[9] H.J. Peng, T.Z. Hou, Q. Zhang, J.Q. Huang, X.B. Cheng, M.Q. Guo, Z. Yuan, L.Y. He, F. Wei, Advanced Materials Interfaces, 1 (2015).

[10] G. Zhou, E. Paek, G.S. Hwang, A. Manthiram, Nat Commun, 6 (2015) 7760.

[11] B. Zhang, X. Qin, G.R. Li, X.P. Gao, Energy \& Environmental Science, 3 (2010) 1531.

[12] J.L. Wang, J. Yang, J.Y. Xie, N.X. Xu, Y. Li, Electrochemistry Communications, 4 (2002) 499-502.

[13] J. Wang, L. Lu, Z. Ling, J. Yang, C. Wan, C. Jiang, Electrochimica Acta, 48 (2003) 1861-1867. 
2018-08-10

Nitrogen-doped micropores binder-free carbon-sulphur composites as the cathode for long-life lithium-sulphur batteries

\author{
Yao, Yuechao
}

Elsevier

Yuechao Yao, Peng Liu, Qi Zhang, et al., Nitrogen-doped micropores binder-free carbon-sulphur composites as the cathode for long-life lithium-sulphur batteries. Materials Letters, Volume 231, 15 November 2018, pp. 159-162

https://doi.org/10.1016/j.matlet.2018.08.046

Downloaded from Cranfield Library Services E-Repository 